\title{
Digitalization of Infrastructural Provision for Agricultural Production
}

\author{
Charykova O.G.* \\ Scientific Research Institute of Economics and Organization \\ of the Agro-Industrial Complex \\ Voronezh, Russian Federation \\ e-mail: chog@narod.ru
}

\author{
Narolina Ju.V. \\ Scientific Research Institute of Economics and Organization \\ of the Agro-Industrial Complex \\ Voronezh, Russia
}

Otinova M.E.

Scientific Research Institute of Economics and Organization of the Agro-Industrial Complex

Voronezh, Russia

\author{
Polunina N.Yu. \\ Scientific Research Institute of Economics and Organization of the Agro-Industrial Complex \\ Voronezh, Russia
}

\begin{abstract}
The subject of the study is the organizational and economic relations that arise in the process of digitalization of infrastructural provision for agricultural production. The aim of the work is the formation of theoretical and methodological provisions for the development of digitalization of infrastructural provision for agricultural production. The article shows the importance of digitalization of infrastructural provision of agricultural production, which can significantly increase the efficiency, quality and productivity of production processes in comparison with traditional forms of management. The general and particular problems concerning the digitalization of both the agro-industrial complex on the whole and the infrastructure objects of agro-industrial production are identified in the article. The importance and the practicability of the digital transformation of agricultural production have been substantiated as the result of the study. The theoretical provisions that reveal the essence and the content of the infrastructural provision for the agro-industrial complex are formulated in the article. The methodical approach to the analysis of the digitalization status of the infrastructural provision of agro-industrial production is substantiated, including the stages of the conduct and the main indicators. The conditions and the factors affecting the digitalization in the agricultural sector both positive and negative are identified. The priority guidelines for the digital transformation of the agricultural production infrastructure have been developed based on the identified problems. The article proposes to consider the infrastructure of agricultural production as a system of elements, institutions and mechanisms that contribute to the production, conservation, physical movement of agricultural products. Digitalization is viewed as the transformation of production and management models based on innovative digital technologies. The application of the proposed methodological approach to assessing the digitalization of infrastructural facilities allows analyzing the degree of use of digital technologies in agricultural enterprises and justifying the need for the introduction of new digital technologies in infrastructural facilities. The practical relevance of the digitalization of infrastructural provision for agroindustrial production is the contribution to the growth of
\end{abstract}

production volumes, the reduction of transaction costs, the increase of physical and economic affordability of food, the promotion of import substitution and the development of interregional exchange and export.

Keywords - infrastructural provision, agro-industrial production, digitalization, infrastructural subsystems, the Internet of things, innovative technologies, digitalization factors.

\section{INTRODUCTION}

Global digitalization, that covers almost all sectors of the economy, is actively being introduced into the agro-industrial complex (AIC). The use of digital technologies can provide agro-industrial production with high productivity growth by reducing costs in all production and logistics chains.

Currently, the main problems of producers are associated with high losses of raw materials and finished commodity at the stage of production, transportation, storage and processing. Therefore, the effectiveness of the functioning of agribusiness enterprises depends to a large extent on timely infrastructure support, which, by its purpose, should help to increase production indicators, the reduce the time it takes for products to move from producer to consumer and transaction costs, and to ensure the uninterrupted provision of agricultural products to consumers (processing, food, light and other industries settings) and food, maintaining and improving quality product specifications.

This thesis actualizes the following areas of the study:

- firstly, the legislative support for the development of market infrastructure has been formed recently. Besides, the program of state support for digitalization in the agricultural sector has been developed. Thus, the infrastructure features, its role and the importance considering the improving of the effectiveness of agricultural production should be clarified; 
- secondly, it is necessary to identify new factors and conditions affecting the infrastructure development in order to enhance the implementation of digital technologies;

- thirdly, the experience of modernization of infrastructure elements (storage systems, goods distribution, exchange) has showed the lack of the efficiency.

Currently, the process of digitalization in the agroindustrial complex is hit-and-miss. The use of IT technologies in most agricultural enterprises is still limited to the use of personal computers, software, technologies for creating and supporting various information resources on the Internet (sites). Therefore, the problem of introduction of digital technologies into the agricultural production system remains unresolved. Accordingly, the topic of this study proves to be actual.

\section{LITERATURE REVIEW}

The scientific research is based on theoretical, methodological and methodic principles developed by foreign and domestic researchers, experience in the formation and application of directions and mechanisms for digital transformation of infrastructural provision for agro-industrial production, proposals and recommendations that determine effective ways of solving problems of increasing the efficiency of agricultural production and ensuring food security of the country based on information and communication technologies.

Many Russian and foreign scientists have made a significant contribution to the development of the theoretical foundations of the problem under study.

Thus, E. Toffler proposed a new ideology for the development of civilizations. He considered three "wave" of the development, namely agrarian, industrial and informative [1]. Subsequently, various aspects of the theory of the information-oriented society were formed by such famous authors as F. Mahlup, M. Porat, M. Castells, J. Massouda and others [2].

The development of the information-oriented society is going on through digitalization. This term was firstly applied in the mid 90-ies of the twentieth century. And at present, digitalization can be understood as the conversion of information into digital form, which helps to reduce costs, increase efficiency, create new opportunities, etc. Digitalization covers business, the production process, the scientific sector, the social sphere and the ordinary life of people, accompanied by the effective use of its results, which are available not only to specialists, but also to ordinary nationals.

The current trends in economic development predetermine the need for the digitalization process in agro-industrial production. At the same time, the greatest return can be obtained by the digitalization of infrastructural provision, which is currently a narrow link in the entire agro-industrial complex.
In general, the problems of the market economy infrastructure were considered for the first time in the economic literature by foreign scientists, including K. Wicksel, H. Singer, R. Johimsen, J. Clark, K. Marx, P. Rosenstein-Rodan, A. Yangson, etc. The bulk of the research was devoted to the analysis of the infrastructure as a whole. The concepts of the formation and development of individual infrastructure subsystems are formulated in the works of T.V. Volyanskaya, A.A. Govorina, Yu.A. Gorskoy, I.A. Dudakova, G.P. Zhuravleva, I.N. Kozelskaya, B.Kh. Krasnopolsky, V.N. Livshitsa, B.Z. Movchan, N.A. Nesterova, E.A. Novikova, A.S. Novoselova, S.S. Nose, E.G. Russian, V.P. Fedko, I.F. Chernyavsky, A.Yu. Sharipova et al [3].

It is necessary to focus on the process of digitalization of infrastructural provision for agricultural production despite the significant amount of work highlighting infrastructure problems. The insufficient study of these issues emphasizes the relevance of the research topic, predetermines its purpose and objectives.

Infrastructure is a constructive component of the process of agricultural production. It is a system of elements, institutions and mechanisms that contribute to the production, conservation, physical movement of products [3], i.e. ensuring the efficiency of reproduction processes. Infrastructure manifests itself in the form of one of the most important areas of production intensification, increasing its efficiency, as well as implementing the social policy of society.

The purpose of the infrastructure is to ensure the production process in the direction ensuring the creating conditions for the growth of volumes and quality of products [4]. Thus, the constant improvement of infrastructure support is required.

It should be noted that the infrastructure was the subject of research by many Russdian scientists (T.V. Volyanskaya, A.A. Govorin, Yu.A. Gorskaya, I.A. Dudakova, G.P. Zhuravleva, I.N. Kozelskaya, B. H. Krasnopolsky, V.N. Livshits, B.Z. Movchan, N.A. Nesterov, E.A. Novikova, A.S. Novoselov, S.S. Nosova, E.G. Russkova, V.P. Fedko, I.F. Chernyavsky, A.Yu. Sharipov, etc.). As a result, the infrastructure is characterized as a combination of industries contributing to the efficient development of industrial and agricultural production and creating conditions for a comfortable life of the population [5-16].

Agro-industrial production affects many areas and industries that are interconnected by organizational and economic relations regarding the production, processing, storage, and sale of products.

Infrastructure fulfills the function of an intermediary between the spheres of the agro-industrial complex (agriculture; sectors engaged in the procurement, transportation, storage and processing of agricultural raw materials; sectors that supply the agricultural sector with means of production) in this process.

Thus, some of the most significant elements can be distinguished as a part of the infrastructural provision for agroindustrial production (Figure 1). 
The state of each element of the infrastructural provision system can be determined by analyzing both the qualitative and the quantitative characteristics.

Thus, the level of development of regulatory, financial and credit, informative and marketing components is characterized by the development of structures (institutions, ministries, departments, units, services and facilities), the effectiveness of the functions they perform, the effectiveness of the measures taken, etc.

The elements of material and production provision are characterized by the quantity and quality of production equipment, vehicles for moving products within the organization, containers for storage, warehousing of products, the presence of processing industries in the organization, etc.

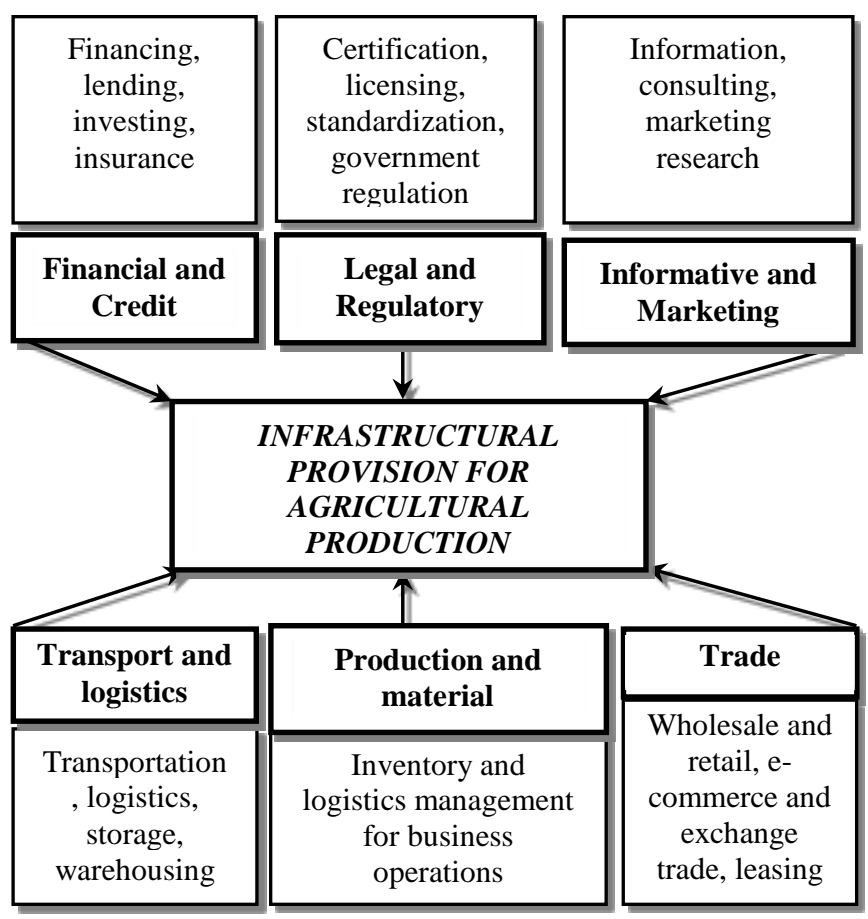

Fig. 1. Elements of infrastructural provision for agricultural production

The transport and logistics subsystem is characterized by the quantity and quality of transport for transporting products from producer to consumer, transportation volumes, transportation costs by various vehicles, storage, processing, warehousing capacities, the presence of logistics centers, the development of innovation, the quality of roads, etc. The trading subsystem can be estimated by analyzing the number of wholesale and retail trade organizations, the volume of goods turnover, the availability of retail facilities, the development of e-commerce and exchange trading, etc.

The functioning of the infrastructure is the process of organizational and economic communications, the result (product) of which is a complex of various services within which the final products of the activities of various organizational infrastructures are realized.

\section{METHODS AND MATERIALS}

The subject of the study is the organizational and economic relations that arise in the process of digitalization of infrastructural provision for agricultural production.

The theoretical basis of the study is the scientific works of Russian and foreign scientists and experts on the development of the infrastructure of the agricultural sector; normative legal acts of the Russian Federation in the field of functioning and regulation of agribusiness.

The purpose of the work is the formation of theoretical and methodological provisions for the development of digitalization of infrastructural provision for agricultural production.

The realization of the research objective has been achieved through the comparative analysis and the identification of key factors contributing to the digitalization of infrastructural provision for agricultural production, the definition of conditions for digitalization at agricultural enterprises, the development of a methodological approach to assessing the digitalization level of the agricultural sector and the substantiation of the priority guidelines for the digital transformation of the agricultural production

The methodological basis of the study is the general scientific methods of cognition (historical, abstract-logical, and dialectical); theoretical generalization method; systemic, functional; factorial, situational and comparative analysis; theoretical and practical works of the authors.

The importance of digitalization of infrastructural provision for agro-industrial production determines the need for a methodological justification of its development level. In this regard, the methodology for the analysis of digitalization of infrastructural provision for agricultural production has been developed as the result of the study based on the analysis and the generalization of various existing methodological approaches (Figure 2).

The important element of the comprehensive assessment of the infrastructural provision for agro-industrial production in the region (including both an assessment of its quantitative composition and the qualitative side) is the assessment of the digitalization level of infrastructural facilities, the equation and the rationality of their distribution in the region. The main purpose of this assessment is to determine the availability of innovative enterprises of the infrastructure complex for agribusiness entities.

Thus, in particular, the practical application of the presented methodological approach to assessing the digitalization of infrastructural facilities ensure the analysis of the degree of modernization of agricultural enterprises, as well as enterprises of processing, storage, distribution, trade (their quantity, capacity, etc.), the justification of the need for the implementation and the adoption of innovative elements of infrastructure within the territory. 
Methodology for the analysis of digitalization of infrastructural provision for agro-industrial production

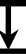

\begin{tabular}{|c|}
\hline $\begin{array}{l}\text { Analysis of factors and conditions affecting } \\
\text { the digitalization of the agro-industrial complex }\end{array}$ \\
\hline \pm \\
\hline $\begin{array}{l}\text { Assessment of infrastructure subsystems digitalization } \\
\text { (regulatory, financial, credit, informative and marketing, trade, } \\
\text { transport and logistics, production and material) }\end{array}$ \\
\hline$\forall$ \\
\hline Assessment of infrastructure facilities digitalization \\
\hline $\begin{array}{l}\text { 1. The volume of innovative digital technologies introduced } \\
\text { in infrastructure facilities }\end{array}$ \\
\hline $\begin{array}{l}\text { 2. The share of infrastructure using cloud services and } \\
\text { artificial intelligence }\end{array}$ \\
\hline $\begin{array}{l}\text { 3. The degree of interconnection of local and national } \\
\text { digital agribusiness platforms }\end{array}$ \\
\hline $\begin{array}{l}\text { 4. The share of eSourcing and sales of agricultural } \\
\text { products }\end{array}$ \\
\hline$\downarrow$ \\
\hline $\begin{array}{l}\text { Evaluation of the effectiveness of the implementation of } \\
\text { digital technologies at infrastructure facilities (gross } \\
\text { production growth due to digitalization) }\end{array}$ \\
\hline
\end{tabular}

Fig. 2. Methodology for the analysis of digitalization of infrastructural provision for agricultural production

\section{RESULTS}

The factors and conditions that affect the digital transformation of infrastructural provision for agricultural production have been identified [17-24]. It is necessary to account them for the development of priority guidelines for the intensification of digitalization processes within the enterprises of the agro-industrial complex.

The external conditions reflect the quality of the legal and regulatory frameworks, the state policy effectiveness in the field of digitalization, the level of the innovative potential development of the agricultural sector, the impact of global trends on the digitalization of the infrastructure of the agricultural sector and the innovative and investment attractiveness of the industry. The internal factors determine the degree of modernization of the material and technical base of the agro-industrial complex infrastructure, the organizational content of the infrastructural provision of the agro-industrial complex, the digitalization level of each infrastructural object, the transformation of the agro-industrial complex labor potential and the mainstreaming of innovative processes. The consideration of both the external conditions and the factors is aimed at substantiating the main directions of technological breakthrough in improving the infrastructural provision of agricultural production based on the adoption of digital technologies (Figure 3). The main positive and negative factors of influence on the process of digitalization of infrastructural provision for agricultural production can be identified based on the ratio of opportunities and risks. The positive factors include the development of new technologies and the increased labor productivity; the modernization of existing and the adoption of innovative infrastructure facilities for agricultural production; the effective regulation of the digital transformation of the agricultural sector; credit availability and others. The negative factors include the lack of financial resources for the introduction of innovative digital technologies in agricultural enterprises; the high depreciation and the technological backwardness of the infrastructure of agricultural production; the imperfection of the legal and regulatory frameworks and their non-compliance with the international standards; the poor level of both the Russian marketing developments in the IT-sphere and the digitalization and the information support for agricultural production and other. The re-thinking of the directions and the mechanisms for implementing the digital transformation of infrastructural provision in the agricultural sector is needed to solve the problems of digitalization of infrastructural provision for agroindustrial production and to overcome negative factors.

\section{CONDITIONS}

(political and economic situation, technical and technological development of the industry, legal and regulatory

frameworks)

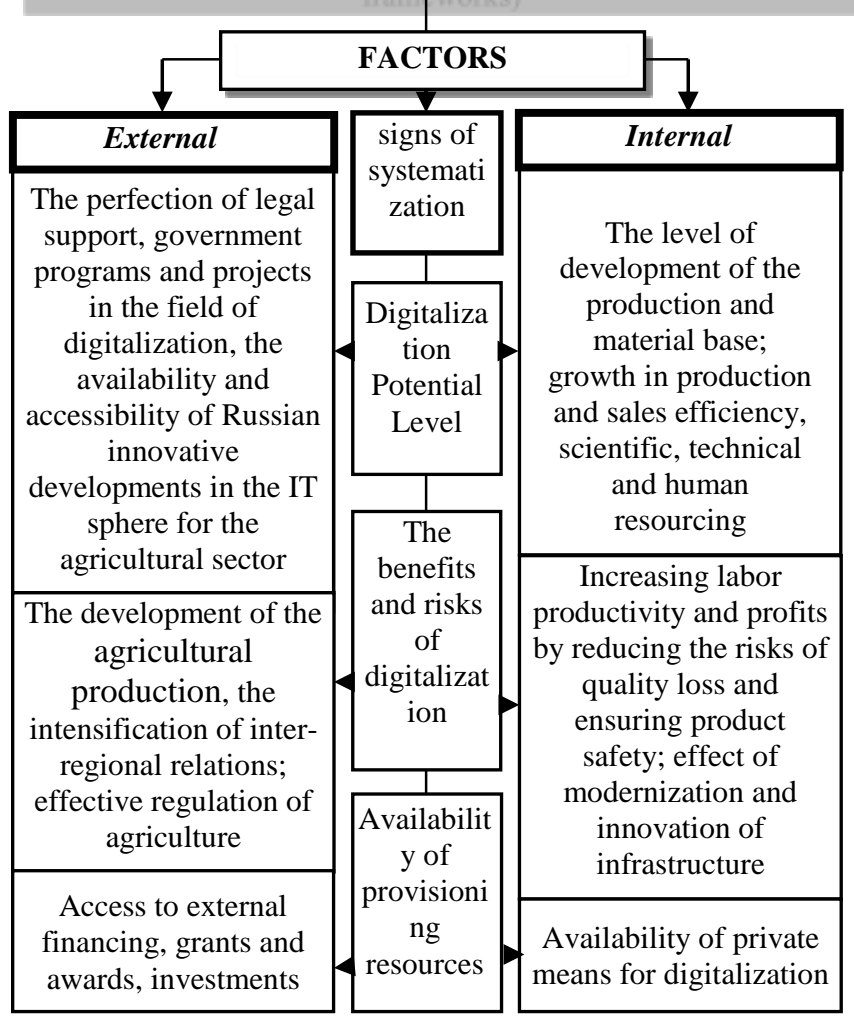

Fig. 3. Factors affecting the digitalization of infrastructural provision for agricultural production

To sum up, the priority guidelines for the digitalization of infrastructural provision for agricultural production in modern conditions will be the following: 
- the transformation and the modernization of the transport and logistics subsystem;

- the creation of a trading subsystem of modern formats;

- the development of the material and production subsystem in compliance with the modern conditions;

- the formation of an innovative information and marketing subsystem;

- increasing the efficiency of the functioning of the regulatory subsystem;

- the improvement of the financial and credit subsystem (Figure 4).

It is necessary to foresee the future strengthening of the social functions of infrastructural support, involving the development and implementation of various social projects for the introduction of digital technologies aimed at improving working conditions and improving the quality of life of rural population while developing mechanisms for implementing the digitalization of infrastructural provision aimed at solving both the economic and the social problems of agricultural production.

In addition, the digital transformation should cover all stages of the reproduction process in the agro-industrial complex and imply the effective interaction of infrastructure entities within the process of development, implementation and replication of digital technologies.

In modern conditions, the digitalization of the information and marketing subsystem in compliance with the changing market conditions and consumer demands is considered to be the important direction in ensuring agro-industrial production is. It is advisable to increase the efficiency and the reliability of information by expanding the range of tasks performed by information and consulting institutions, namely: providing information and consulting services and assisting agricultural enterprises in making grounded decisions in order to increase efficiency and sustainability; dissemination of new knowledge and scientific developments in the field of IT-technologies; meeting the needs of agricultural producers in information about innovative software products for digitalizing the production, storage, processing and sale of manufactured products. In the context of the globalization of the agroindustrial economy and the increasing role of Russia in the global agri-food market, the rapid development of infrastructure support for agro-industrial production based on digitalization requires constant monitoring of global and domestic innovative developments in the field of digital technologies.

The important elements that ensure the speedy exchange of information in the economic activities of agricultural enterprises are various means of communication, the operation of which is provided by the relevant organizations.

The current focus on digitalization should also apply to infrastructure elements of communication. However, with regard to the telephone network, the level of its digitalization in the regions of Central Russia has not reached the required level yet.

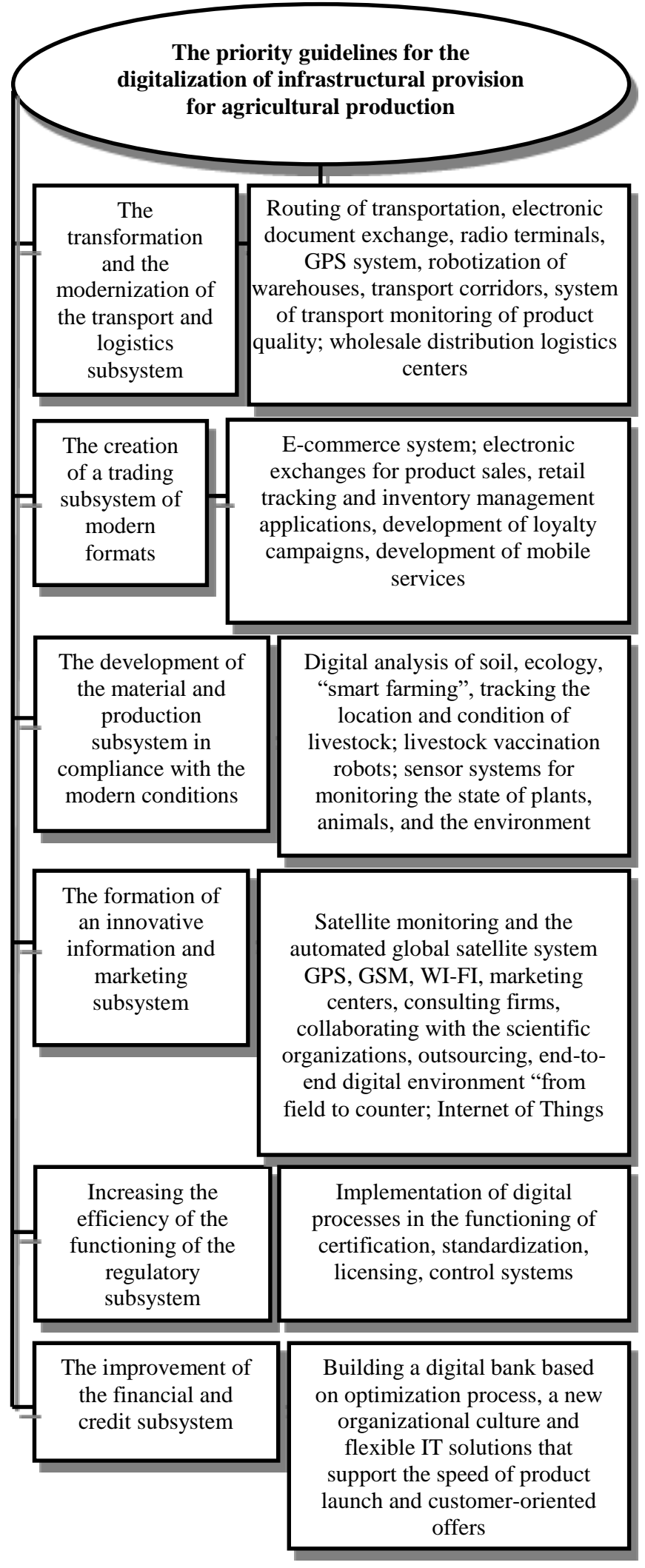

Fig. 4. Priority guidelines for the digitalization of infrastructural provision

One of the indicators of its progress is a complex of technologies, united by the common name of the Internet of things. The market share amounted to $6 \%$ of all projects 
implemented in the world in the field of the Internet of things in the agricultural sector, as on January 2017.

As the research showed, the inadequate coverage of the Russian territory with mobile radiotelephone (cellular) communication is a negative point, depriving the agroindustrial complex of mobility. In addition, the share of the population having the ability to connect to the Internet using broadband access, including wireless has not reached the $100 \%$ level. The fact indicates the certain lack of the ability to inform agricultural enterprises.

The low level of staff graduates qualification is considered to be the important problem of digitalization of the agroindustrial complex as a whole and its infrastructure facilities is. There are about 113 thousand specialists in the field of information technology who are employed in the agroindustrial complex in Russia. There is 1 employee with knowledge of information and communication technologies per 1000 employees. We need to attract at least 90-100 thousand IT-specialists to the industry in order to achieve the performance of developed countries.

At present, there is not a unified information system containing up-to-date information on innovative products for agricultural production in Russia. Software for agro-industrial enterprises is developed and implemented for specific rather narrow production tasks that are neither informationally nor functionally related. There are no complex information systems that can give the expected positive effect. The use of digital technologies involves the formation of national information systems aimed at accounting for agricultural land, the creation of all-Russian interactive soil map, monitoring the quality of products, determining inter-regional exchange and forecasting the level of food supply. The national digital platform should offer the possible options for lending, insurance and subsidizing of ongoing innovative projects, as well as the personal package of innovative solutions for digitalizing infrastructure facilities in the agro-industrial complex.

In particular, it is recommended to create the remote access system for counseling and training events (including Internet consulting); to create the electronic library of relevant legal and regulatory frameworks, references and consulting materials and to provide access to them; to increase the number of scientific and practical conferences on pressing problems of infrastructure support for agro-industrial production; to create the research and production centers that carry out training functions; to intensify exhibition and propaganda activities in the field of achievements of market entities.

The functioning of digital platforms should also lead to the formation of a system of analysis, assessment and forecasting of the state of agro-industrial production, which enables all interested parties to provide timely reliable information regarding the areas of production and implementation.

The promotion of agricultural products from producers to consumers in order to meet the demands of the latter is determined by the presence of efficiently functioning subsystems of the trade infrastructure.
For the development of this subsystem, it is advisable to introduce:

- Blockchain technologies (creation of a common information space through a blockchain network with suppliers and partners);

- virtual digital assistants;

- mobile applications with augmented reality;

- smart contract technologies (electronic algorithm for interaction with suppliers);

- artificial intelligence technologies;

- projects of warehouse robotization, control of product integrity and cost reduction, modernization of network infrastructure.

\section{CONCLUSION}

The practical implementation of the directions for the future development of digitalization of the infrastructure of agricultural production will contribute to:

- the preservation of the required product quality (and, possibly, its improvement) during physical transfer from the production sector to the sphere of consumption, delivery of goods to the consumer at the right time, the right amount, the required species diversity, completeness, packaging based on the provision of services by infrastructure organizations;

- the minimization of material, financial and labor costs, the reduction of losses during the physical movement of products from production to consumption;

- the optimal and rational organization of warehousing and storage of products, the reduction of costs associated with transportation, due to the organization of the cargo system through the implementation of logistic approaches;

- the reduction of costs and terms of operations through the timely receipt of information on the situation, the location of products, delivery conditions through the formation of information and analytical data banks by market entities;

- the reduction of terms of payments and capital circulation;

- the creating of favorable conditions for a civilized trade due to the development of a regulatory framework and methodological tools in compliance with modern conditions.

The implementation of these guidelines will significantly improve the functioning of the agro-industrial complex on the whole.

The infrastructure ensures the interconnection of market entities. This results in the association of the level of its development with the functioning of the necessary elements of the transport and logistics subsystem and with the effectiveness of relations between them. 
The research showed that it is necessary to subject significant changes to the storage system. Its main functions are to ensure the preservation of the volume and quality of all produced and processed agricultural products, raw materials and food, reducing the time and costs associated with the physical movement of products due to the modernization of material and technical objects of the system storage and warehousing and their inclusion in the structure of distribution and logistics systems.

In the near future, it is necessary to solve the most important issues for the agro-industrial complex related to expanding access for agricultural producers to sales markets through the development of a multi-format trade infrastructure, strengthening cooperative ties in the production and sale of products, and limiting the monopolization of retail chains. This will allow taking into account the multilateral interests of food producers and their direct consumers, as well as trade organizations.

\section{References}

[1] E. Toffler, Third Wave. Moscow: Publ. House "AST", 2010, 784 p.

[2] M. Porat, The Information Economy: Definition and Measurement. Washington, DC: Publ. by the US Government Printing Office, 1977, $231 \mathrm{p}$.

[3] O. Charykova, E. Zakshevskaya, E. Salnikova, E. Popova, N. Polunina, "Infrastructure of agro-food market: theory, analysis, concept", Voronezh: Pub. by the FGBNU NIIEOAPK of Central Black Earth District of the Russ. Feder., 2019, 140 p.

[4] A. Novoselov, T. Volyanskaya, Problems of market infrastructure management in the regions of Siberia, In: Problems of innovative management of the economy of the regions of Siberia: collection of scientific works, under the ed. A. Novoselov, V. Seliverstov. Novosibirsk: Instit. of Econ. and Organizat. of Industr. Product. of the Siber. Branch of the Russ. Acad. of Sci., 2015, pp. 256-269.

[5] A. Govorin, Formation and development of market infrastructure in Russia. Moscow, 2001, $352 \mathrm{p}$.

[6] E. Novikova., Yu. Gorskaya, "Organization of commercial activity in market infrastructure", The manual for the students studying in the direction of preparation 38.03.06 "Trade business" (Commerce profile). Saratov: Publ. by the Saratov soc. and econ. instit. (branch) FGBOU VPO "REU of G.V. Plekhanov", 2015, 24 p.

[7] I. Dudakova., V. Fedko, "Retail infrastructure development", Marketing, 2010, vol. 3, pp. 97-107.

[8] K. Howard, G. Zhuravleva, Principles of the Economy of the Free Market System (Economy). Moscow: Publ. by the Zlatoust, 1995, 326 p.

[9] I. Kozelskaya, A. Kozelskiy, "Functioning of infrastructure organizations in the modern conditions of the Russian economy", J. of the Saratov State Socio-Econ. Univer., vol. 4, no. 63, pp. 34-38, 2016.
[10] B. Krasnopolsky, The Role of Scientific and Institutional Infrastructure in Synthesis of Forecasts of Scientific, Technological and SocioEconomic Development of Macroregion, In: Russia: Trends and Prospects of Development, Yearbook. Responsible editor V. Gerasimov. Moscow, 2016, pp. 701-705.

[11] B. Krasnopolsky. Role of scientific and institutional Lishchitz V, In Problems of functioning and development of infrastructure of the national economy. Moscow, 1989, pp. 12-124.

[12] B. Movchan, N. Chikovsky, "Integrated Approach to Infrastructure Industries Development", Econ. Sci., vol. 2, pp. 95-97, 1981

[13] N. Nesterov, Organization and complex infrastructure planning. Moscow: Publ. by the Minvuz, 1986, pp. 10-21.

[14] S. Nosova, Infrastructure in the system of public production: tutorial. Moscow, 1982, pp. 4-183.

[15] I. Chernyavsky, Infrastructure of agricultural production: Issues of theory and practice. Moscow: Publ. by the Econ., 1979, pp. 11-193.

[16] A. Sharipov, Economic Essence of Infrastructure in Socialism, In: Management of Infrastructure Branches in the System of the Region, A Coll. of Sci. Works. Leningrad: Publ. by the Leningrad State Univer., 1980, pp. 4-5.

[17] Departmental project "Digital Agriculture": official edition. Moscow: Publ. by the FGBNU "Rosinformagrotech", 2019, 48 p. Retrieved from: http://mcx.ru/upload/iblock/900/900863fae06c026826a9ee43e124d058. pdf

[18] A. Chekunov, "Technological modernization of agricultural production: condition, forms, methods and directions of innovations support", Proc. of the Voronezh State Univer. of Engineer. Technol., vol. 81, no. 1, pp. 373-379, 2019. Retrieved from: https://doi.org/10.20914/2310-12022019-1-373-379

[19] N. Serebryakova, A. Petrikov, "The principles of design and the organization of functioning of innovative infrastructures in the conditions of the Industry 4.0", Proc. of the Voronezh State Univer. of Engineer. Technol., vol. 80, no. 4, pp. 384-387, 2018. Retrieved from: https://doi.org/10.20914/2310-1202-2018-4-384-387

[20] O. Charykova, E. Markova, "Regional Clustering in the Digital Economy", Econ. of Reg., vol. 15, no. 2, pp. 409-419, 2019. Retrieved from: https://doi.org/10.17059/2019-2-8

[21] N. Kashapov, M. Nafikov, M. Gazetdinov, S. Gazetdinov, A. Nigmatzyanov, "Modern problems of digitalization of agricultural production”, IOP Conf. Ser. Mater. Sci. and Engineer., p. 012044, 2019. Retrieved from: https://doi.org/10.1088/1757-899X/570/1/012044

[22] A. Shamin, O. Frolova, V. Makarychev, N. Yashkova, L. Kornilova, A. Akimov, "Digital transformation of agricultural industry", IOP Conf. Ser. Earth and Environmental Sci., p. 012029, 2019. Retrieved from: https://doi.org/10.1088/1755-1315/346/1/012029

[23] E. Gusakova, A. Shchutskaya, E. Afanaseva, "Digital technologies as a tool for solving basic industrial problems in the agro-industrial complex", Lecture Notes in Networks and Syst., vol. 84, pp. 172-179, 2020. Retrieved from: https://doi.org/10.1007/978-3-030-27015-5_22

[24] I. Gorlov, G. Fedotova, A. Glushchenko, M. Slozhenkina, N. Mosolova, "Digital technologies in the development of the agro-industrial complex", Lecture Notes in Networks and Syst., vol. 87, pp. 220-229, 2020. Retrieved from: https://doi.org/10.1007/978-3-030-29586-8_26 